\title{
On Utilitarianism and Utilitarian Attitudes
}

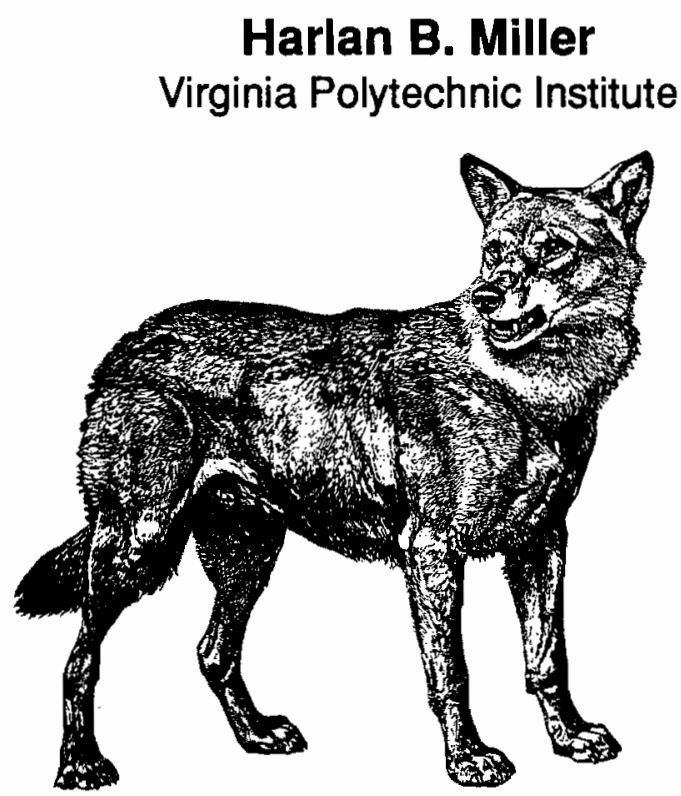

Moral philosophers, like other professional groups, use a body of technical terminology. Some of this technical vocabulary is too unusual to be misapprehended. 'Deontology' and 'consequentialism', for examples, have no normal English uses and so are unlikely to confuse an outsider. (Obscurity, yes, but not confusion.) Confusion is much more likely when a technical term also has non-technical uses. Such confusion, I fear, fairly frequently arises in connection with the terms 'utilitarianism' and 'utilitarian'.

'Utilitarianism' in moral philosophy refers to a theory of right action classically developed by Jeremy Bentham, John Stuart Mill, and Henry Sidgwick. On this theory the right act to choose in any situation is the one that will produce the greatest balance of pleasure over pain for all affected beings. If no act is available that will produce net pleasure, that act is right that will produce the least net pain.

Utilitarianism comes in many forms (probably over a hundred if one counts all the variants), depending on whether the principle is applied to choices of acts or choices of rules, on how broadly or narrowly 'pleasure' and 'pain' are understood, on whether it is pleasure or

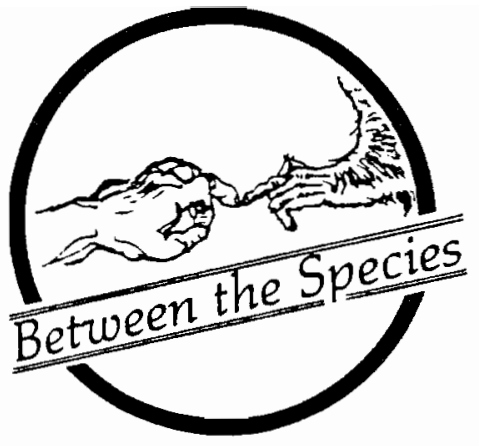

preference satisfaction that is to be maximized, on how wide a scope is covered by 'all affected beings', on whether it is a matter of actual or of expected consequences, and so on.

Utilitarianism in all its forms is a consequentialist theory: what makes right acts right is their consequences.

Very few modem moral philosophers are indifferent to utilitarianism. The theory, in its many versions, has lots of champions. Peter Singer is probably the unabashed utilitarian best known to animal people. Tom Regan is one of many who think utilitarianism deeply mistaken. A third large group, of which I am a member, think that utilitarianism is almost surely part of any acceptable moral theory, but not the whole story.

Among moral philosophers the word 'utilitarian' serves as an adjective meaning something like 'of the sort connected with utilitarianism' and as a noun referring to proponents of utilitarianism.

In the nonacademic world the 'utilitarianism' has no ordinary use. The word 'utilitarian' serves as an adjective describing an attitude. To take a utilitarian attitude toward something is to value it only for its usefulness (utility) as a means to some end. One takes a utilitarian attitude to other people if one considers them important only insofar as they impede or facilitate one's own (or one's cause's) pleasure, promotion, or

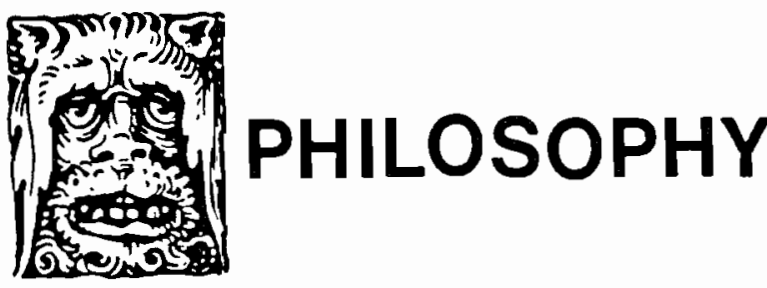


power. A utilitarian attitude toward a tree values the tree, if at all, as lumber, or perhaps as shade, but not for its beauty and certainly not for its own sake. The utilitarian attitude toward animals is demonstrated by factory farms and the naming of state departments of 'natural resources'.

Utilitarianism, in most of its versions, is directly opposed to such a utilitarian view of animals. The pleasure and pain (or satisfaction and frustration) of sentient beings is directly valued (positively or negatively) by utilitarianism. The suffering of animals matters directly. No real utilitarian (proponent of utilitarianism) takes a utilitarian attitude (all that matters is usefulness) toward a sentient being.

The confusion of the two senses of 'utilitarian' is made even more likely by a common objection to utilitarianism. Thisobjection is that utilitarianism would in many circumstances require the sacrifice of a minority to maximize the satisfactions of the majority. Maybe so, maybe not (the literature on the argument is immense). But even in such a case utilitarianism requires that the interests of all be taken equally into account. No affected sentient being can be treated just as a means to the ends of others.

Whatever else they may do, utilitarians don't take a merely utilitarian view of animals.

\section{SOCIETY FOR THE STUDY OF ETHICS AND ANIMALS}

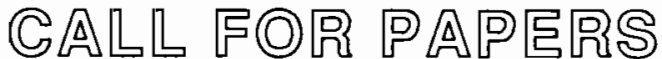

\section{EASTERN, PACIFIC, AND CENTRAL DIVISIONS}

The Society for the Study of Ethics and Animals meets in conjunction with the divisional meetings of the American Philosophical Association. Papers are hereby invited for the December, 1991, Eastern meeting, the March, 1992, Pacific meeting, and the April, 1992, Central meeting.

Papers are welcome on any topic connected with ethical issues affecting nonhuman animals. Possible topics include:

- The moral (in)significance of being natural (rather than domesticated or genetically engineered)

- The consonance (or lack thereof) of Animal Liberation Front actions with on animal rights ethic

- Historical studies of conceptions of the moral standing of animals

- Animals and the action ethics/virtue ethics distinction

- The importance of animal issues to philosophy and philosophers
- Companion animals and paternalism

- The ethics and epistemology of animal research and so on.

The Society employs a system of blind reviewing for the selection of papers for its programs. Papers must be ten to fifteen pages long, double-spaced. Three copies are required, with the author's name and any other identifying information on a separate title page. Send papers to Professor Harlan B. Miller, Society for the Study of Ethics and Animals, Department of Philosophy, Virginia Polytechnic Institute and State University, Blacksburg, Virginia 24061-0126. Be sure to indicate which meeting is desired. Volunteers to comment on papers should submit their names to the same address. Deadlines are as follows:

\section{Eastern meeting March 15, 1991 \\ 1992 Pacific meeting September 1,1991 \\ 1992 Central meeting September 1,1991}

Papers accepted for meetings will automatically be considered for publication in Between the Species. 